\title{
Percutaneous kyphoplasty for the treatment of very severe osteoporotic vertebral compression fractures with spinal canal compromise
}

\author{
Heng Wang ${ }^{1 \dagger}$, Zongyu Zhang ${ }^{2 \dagger}$, Yijie Liu ${ }^{1}$ and Weimin Jiang ${ }^{1 *}$
}

\begin{abstract}
Background: Very severe osteoporotic vertebral compression fractures (vsOVCFs) are osteoporotic vertebral compression fractures with vertebral body collapse to less than one third of their original height. Few data are available about the use of percutaneous kyphoplasty (PKP) in treating vsOVCFs with spinal canal compromise. The aim of this study was to evaluate the safety and efficacy of percutaneous kyphoplasty (PKP) for the treatment of vsOVCFs with spinal canal compromise.

Methods: Thirty-five patients who suffered vsOVCFs with spinal canal compromise but without neurological deficits were treated by PKP between January 2009 and October 2014. The vertebral height, local kyphotic angle (LKA), visual analogue scale (VAS) and Oswestry Disability Index (ODI) values were assessed before the operation, 1 day after the operation and at the final follow-up.

Results: Significant improvements on the VAS and ODI were noted 1 day post-operatively $(p<0.01)$, and these results were preserved at the final follow-up. The vertebral height was restored and the LKA was improved after surgery $(p<0.01)$. No neurological deterioration was found. Five of 35 vertebrae $(14.3 \%)$ of cement leakages were all asymptomatic. Four new OVCFs in three patients were identified.

Conclusion: PKP is a safe and effective procedure for the treatment of vsOVCFs with spinal canal compromise, achieving significant vertebral height restoration and kyphotic angle reduction and leading to a significant pain relief and improvement in function.
\end{abstract}

Keywords: Kyphoplasty, Osteoporosis, Very severe osteoporotic vertebral compression fracture, Spinal canal compromise

\section{Background}

Osteoporotic vertebral compression fracture (OVCF) is a common cause of pain and disability in the elderly population, affecting 1.4 million people each year worldwide [1]. Conservative management, including bed rest, pain relievers, bracing and physical therapy, may fail to relieve pain and frequently lead to prolonged

* Correspondence: jwmpaper@126.com

${ }^{\dagger}$ Equal contributors

${ }^{1}$ Department of Orthopaedic Surgery, The First Affiliated Hospital of

Soochow University, 899 Pinghai Road, Suzhou, China

Full list of author information is available at the end of the article immobilisation, depression and a substantial negative impact on life quality [2-4].

Percutaneous kyphoplasty (PKP) is a minimally invasive procedure for the treatment of OVCFs, and numerous encouraging studies have been reported $[2,5,6]$. However, there have been only few reports on the role of PKP in the treatment of very severe osteoporotic vertebral compression fractures (vsOVCFs), which are the vertebral body collapse to less than one third of their original height $[7,8]$. Even less data are available about the use of PKP in treating vsOVCFs with spinal canal compromise. 
Here, we report on our experience of the treatment for vsOVCFs with spinal canal compromise by PKP. The purpose of our study was to evaluate the efficacy and safety of PKP for the treatment of vsOVCFs with spinal canal compromise.

\section{Methods}

\section{Study population}

A total of 35 patients who suffered from vsOVCFs with spinal canal compromise at one level underwent PKP between January 2009 and October 2014. The mean age of the patients was 71.7 years old (65 to 82 ). The mean duration of symptoms was 5.3 months (1.5 to 10). All the patients had osteoporosis, which was preoperatively identified by dual-energy X-ray absorptiometry (DXA). The mean $T$ score was $-4.05 \pm 0.76(-5.6$ to -3.1$)$ as measured from the L-spine. All the patients had severe back pain which was refractory to conservative therapy, such as bed rest and treatment with analgesics and antiosteoporotic medication. The pain region was consistent with the presence of oedema in the fractured vertebra found on MRI. Patients were excluded due to the presence of pathologic compression fractures, neurologic deficits and spinal cord compression syndrome. The treated levels were localised in the thoracic spine and the lumbar spine with majority between T12 and L2 (Fig. 1). This study was approved by the Institutional Ethics Committee of Soochow University.

\section{Surgical technique}

All PKP procedures were performed under general anaesthesia using fluoroscopic guidance. Patients were placed in the prone position with a bolster placed under the sternum and pelvis. Guide wires were inserted in order to obtain bilateral transpedicular access to the fractured vertebral body. The opening was gradually enlarged using successively larger cannula. Kyphon balloon tamps (Kyphon Inc., Sunnyvale, CA, USA) were inserted through the working channel and placed in the anterior three fourths of the vertebral body in the lateral view. The balloons were then inflated slowly to reduce the fracture and to create a cavity for the injection of cement. The inflation was stopped when the pressure reached 200 psi or the balloon contacted the endplate. They were then deflated and removed. Polymethylmethacrylate (PMMA) cement was injected incrementally to fill the cavity when it became doughy and could stand at the tip of the bone cement inserter. The entire injection process was monitored continuously under fluoroscopic control in the lateral view. The procedure was stopped immediately if high resistance was encountered or if PMMA neared the posterior wall of the vertebral body. The amount of cement was noted. The patients were discharged 1 day after the procedure and were referred for anti-osteoporosis treatment in the outpatient department.

\section{Data collection and outcome assessment}

We recorded clinical and radiological evaluations at preoperation, post-operation (1 day after surgery) and final follow-up.

Visual analogue scale (VAS; scored from 0 to 10: 0 , no pain; 10, the worst imagined) was used to evaluate the pain, and Oswestry Disability Index (ODI) score was used as a functional assessment.

The anterior and middle heights of the vertebra were measured on standing lateral radiographs. The normal height of the fractured vertebra was estimated from the mean of the measurements from the closest normal vertebra cephalad and caudad to the treated level. The vertebral height ratios were calculated as follows: (fractured vertebral height/mean adjacent control vertebral height) $\times 100 \%$ [9]. Local kyphotic angle (LKA) was calculated using the Cobb method: the angle formed

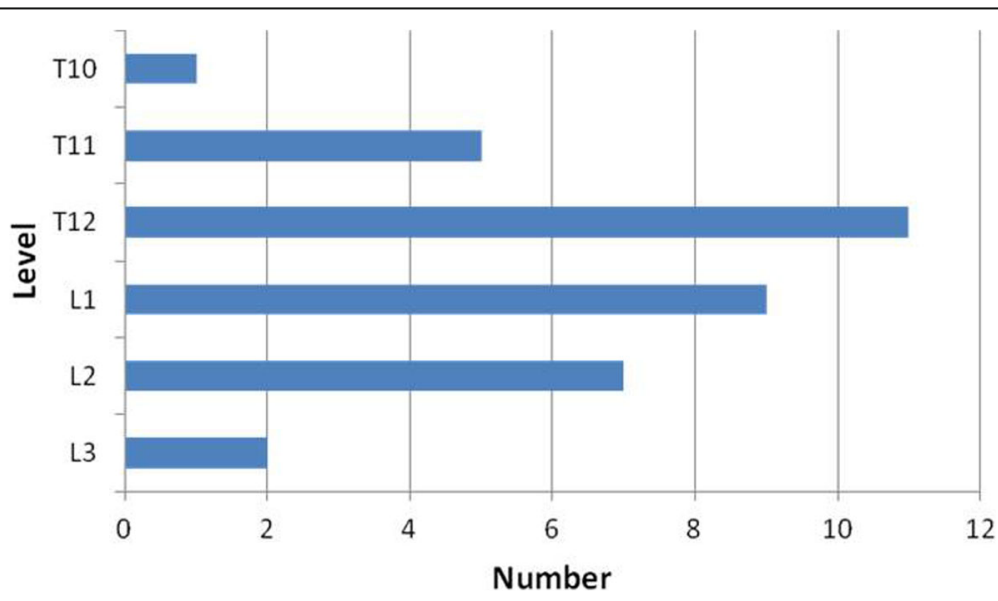

Fig. 1 The distribution of levels treated by PKP among 35 patients suffering from vsOVCFs with spinal canal compromise 
between a line drawn parallel to the superior endplate of the vertebra one level above the fracture and a line drawn parallel to the inferior endplate of the vertebra one level below the fracture.

\section{Statistical analysis}

Data were presented as mean \pm SD. The Statistical Package for the Social Sciences software (version 16.0, SPSS, Chicago, IL, USA) was used for the analysis. Comparisons of clinical and radiological outcomes pre- and postoperatively were made using a paired $t$ test. Differences were considered statistically significant when $p<0.05$.

\section{Results}

All 35 patients tolerated the operation well. No neurological deterioration was found. The average operative time was $41.3 \pm 5.4(32-51) \mathrm{min}$. The average cement volume was $4.95 \pm 0.68(3.5-6.0) \mathrm{ml}$. The mean followup was $34.0 \pm 8.1(18-48)$ months.

All patients achieved substantial pain relief after surgery. The VAS score decreased significantly from a pre-operative value of $8.3 \pm 1.1$ to a post-operative value of $2.6 \pm 0.8$ and was maintained at $2.8 \pm 0.8$ at the final follow-up. The ODI score decreased significantly from a pre-operative value of $76.6 \pm 12.9$ to a post-operative value of $34.3 \pm 7.7$ and was $35.5 \pm 9.3$ at the final followup (Table 1).

Significant increases of the anterior and middle vertebral heights were observed after surgery, and the vertebral heights maintained throughout the period of follow-up. The mean improvement in LKA was $9.3^{\circ}$, and the correction was maintained at the final follow-up (Fig. 2, Table 2).

Asymptomatic cement leakage occurred in 5 of 35 cases (14.3\%) with 2 cases into the intervertebral space, 2 cases lateral to the vertebral body and 1 case into the paravertebral vein. During the period of follow-up, three patients had developed four new symptomatic OVCFs and underwent additional PKP to relieve pain. There was no infection, pulmonary embolism and patient death.

\section{Discussion}

The treatment for vsOVCFs with spinal canal compromise but without neurological deficits remains controversial. Conservative treatment does not appear to be effective for painful vsOVCFs, which often results in many

Table 1 Mean improvement in VAS and ODI

\begin{tabular}{llll}
\hline & Pre-operative & Post-operative & Last follow-up \\
\hline VAS & $8.3 \pm 1.1$ & $2.6 \pm 0.8^{\mathrm{a}}$ & $2.8 \pm 0.8^{\mathrm{a}}$ \\
ODI (\%) & $76.6 \pm 12.9$ & $34.3 \pm 7.7^{\mathrm{a}}$ & $35.5 \pm 9.3^{\mathrm{a}}$ \\
\hline
\end{tabular}

VAS visual analogue scale, ODI Oswestry Disability Index

${ }^{\mathrm{a}} \mathrm{P}<0.01$ compared to pre-operative value complications, such as pulmonary deterioration, deep vein thrombosis, weight loss and depression [3, 10]. Open surgery is also inappropriate in these patients due to severe surgical trauma, difficulty of fixation and long time of bedding $[11,12]$.

Percutaneous vertebroplasty (PVP) and PKP have been proven to be safe and effective to treat OVCFs time and time again $[2,5,6,13-15]$. However, in vsOVCFs with spinal compromise, many authors considered these two procedures to be relatively or even absolutely contraindicated because of technical difficulty, high risk of cement leakage and further spinal canal compromise [16-19]. Nevertheless, the literature and our own experience demonstrate this assertion to be unfounded. Some studies reported good results with PVP owing to its analgesic and stabilising effects in the treatment of osteoporotic vertebral fractures with spinal canal compromise $[18,20,21]$. There are also some studies proving that PVP can be used in vsOVCFs with satisfactory results $[7,8,22]$. In our study, the VAS and ODI scores decreased significantly after the procedure, demonstrating that PKP could provide rapid, marked, and sustained improvements in pain and function in the treatment of vsOVCFs with spinal compromise.

In vsOVCFs with spinal canal compromise, needle placement is technically demanding, because of the extreme kyphotic angle and the severe vertebral collapse. In our study, to avoid perforating the endplate, a low lateral transpedicular approach was adopted and bilateral double balloon inflation was performed to achieve en masse reduction [23] in all cases.

Cement extravasation is the most common complication in PKP and PVP. Cement leakage into the spinal canal is devastating, resulting in spinal cord or nerve injury. In vsOVCFs with spinal compromise, the posterior vertebral walls are deficient and other peripheral vertebral walls are frequently damaged as well. Therefore, the risk of cement leakage is very high. Young et al. [22] reported that cement leakage was demonstrated in $72 \%$ cases using PVP for vsOVCFs. Nieuwenhuijse et al. [7] reported that cement leakage occurred in $91.9 \%$ of vsOVCFs treated by PVP. Li et al. [21] showed that cement leakage rate was $47.8 \%$ using PVP for the treatment of osteoporotic vertebral fractures with spinal compromise. In the current study, cement leakage occurred in 5 of 35 treated vertebra (14.3\%). The lower cement leakage rate could be ascribed as follows: (1) The cavity created by balloons provided space for bone cement filling under conditions of high viscosity and low pressure. (2) We inflated the balloons slowly and moderately to avoid excessive reduction of the fracture which may cause new defects of the vertebral body. (3) We controlled the cement with a doughy consistency, which did not stick to the finger and could stand erect at the 

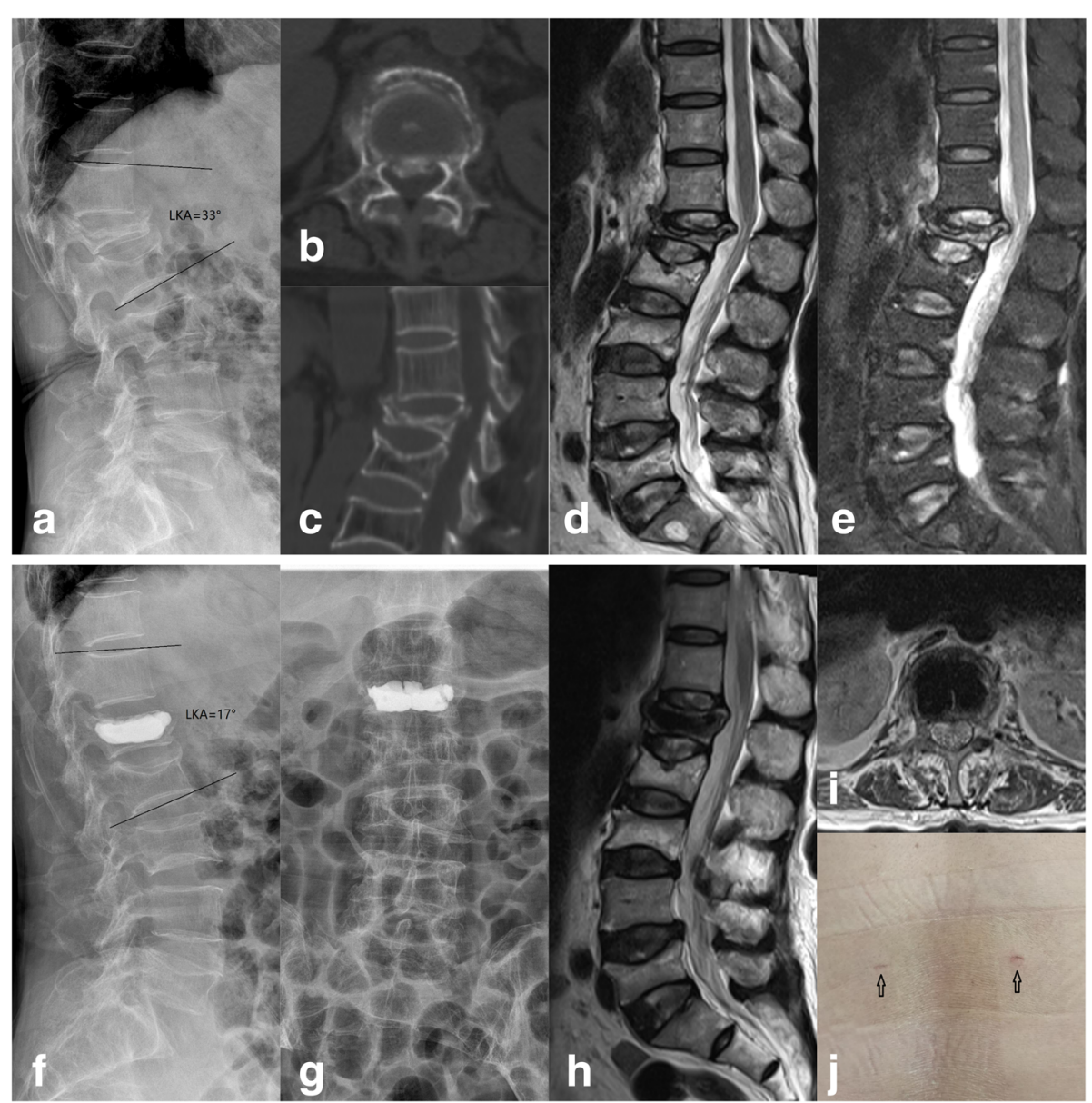

Fig.2 A 69-year-old woman suffered L1 vsOVCF with spinal canal compromise treated with percutaneous kyphoplasty. a The pre-operative kyphotic angle was $33^{\circ}$. b, c Pre-operative CT showed retropulsion of the posterior wall fragment into the spinal canal. $\mathbf{d}$, e The pre-operative MRI displayed high signal intensity in the vertebral body in T2-weighted and short tau inversion recovery (STIR) images. $\mathbf{f}, \mathbf{g}$ The post-operative X-ray films showed cement distributed well and did not leak. The kyphotic angle was $17^{\circ} . \mathbf{h}, \mathbf{i}$ The post-operative MRI showed reduction of the retropulsed bone fragment from the spinal canal. $\mathbf{j}$ The minimal incisions of PKP (black arrows)

tip of the bone cement syringe when pushed out, to block some cortical defects and segmental veins [24]. (4) Continuous $\mathrm{C}$-arm X-ray monitoring was performed during the entire gradual injection process. Injection was stopped immediately when $1 / 4$ of the distance to the posterior wall of the vertebral body remained. (5) For

Table 2 Mean improvement of radiographic data

\begin{tabular}{llll}
\hline & Pre-operative & Post-operative & Last follow-up \\
\hline $\begin{array}{llll}\text { Vertebral body } \\
\text { height ratios }(\%)^{\mathrm{a}}\end{array}$ & & & \\
Anterior & $26.5 \pm 4.2$ & $53.6 \pm 4.0^{\mathrm{b}}$ & $51.2 \pm 3.9^{\mathrm{b}}$ \\
Middle & $30.9 \pm 4.5$ & $60.9 \pm 4.3^{\mathrm{b}}$ & $57.4 \pm 4.2^{\mathrm{b}}$ \\
LKA $\left(^{\circ}\right)$ & $25.1 \pm 5.0$ & $15.3 \pm 5.5^{\mathrm{b}}$ & $15.7 \pm 5.8^{\mathrm{b}}$
\end{tabular}

LKA local kyphotic angle

${ }^{a}$ Vertebral body height ratios $(\%)=($ fractured vertebral body height $/$ normal vertebral body height) $\times 100 \%$

${ }^{\mathrm{b}} P<0.01$ compared to pre-operative value patients with the anterior wall deficiency, a small amount of mid- to later-stage cement in dough phase was first injected to block the defect of the anterior wall. After the filling solidified, earlier stage cement in dough phase was then injected.

Several studies have demonstrated that, compared to PVP, PKP can effectively correct kyphosis and improve vertebral body height $[25,26]$. In vsOVCFs with spinal canal compromise, the severe compression fracture generated a backward force which resulted in bone fragment displacement into the spinal canal. The balloon inflation can distend the vertebral body to partially restore its height, which would counterbalance the backward force. If related ligaments are structurally complete, the distention of the vertebral body can make the ligaments tense to retract protruded bone fragments. In the present study, significant post-operative correction of the kyphosis and restoration of the vertebral height were 
observed and were not lost during follow-up. No neurological deterioration was found.

The limitations of our study are its retrospective nature and small number of patients. A further limitation is the lack of a control group. Thus, further large-scale prospective randomised controlled studies are required.

\section{Conclusion}

PKP is a safe and effective procedure for the treatment of vsOVCFs with spinal canal compromise, achieving significant vertebral height restoration and kyphotic angle reduction and leading to a significant pain relief and improvement in function.

\section{Acknowledgements}

We are very grateful to Professor Huilin Yang for his valuable suggestions on this work.

\section{Funding}

No funds were received in support of this work.

\section{Availability of data and materials}

The datasets used and/or analysed during the current study are available from the corresponding author on reasonable request.

\section{Authors' contributions}

WJ conceived of the study, participated in its design and coordination, and helped to draft the manuscript. HW and ZZ drafted the manuscript. HW and $Y L$ participated in the design of the study, performed the statistical analysis, and helped to revise the manuscript. All authors read and approved the final manuscript.

\section{Ethics approval and consent to participate}

This study was approved by the Institutional Ethics Committee of Soochow University. Consent to participate was obtained from the participants.

\section{Consent for publication}

Written informed consent for publication was obtained from all patients.

\section{Competing interests}

The authors declare that they have no competing interests.

\section{Publisher's Note}

Springer Nature remains neutral with regard to jurisdictional claims in published maps and institutional affiliations.

\section{Author details}

${ }^{1}$ Department of Orthopaedic Surgery, The First Affiliated Hospital of Soochow University, 899 Pinghai Road, Suzhou, China. ${ }^{2}$ Department of Orthopaedic Surgery, Lianyungang Affiliated Hospital of Nanjing University of Chinese Medicine, 148 Chaoyang Road, Lianyungang, China.

Received: 17 October 2017 Accepted: 9 January 2018 Published online: 17 January 2018

\section{References}

1. Johnell O, Kanis JA. An estimate of the worldwide prevalence and disability associated with osteoporotic fractures. Osteoporos Int. 2006;17(12):1726-33.

2. Chen L, Yang H, Tang T. Unilateral versus bilateral balloon kyphoplasty for multilevel osteoporotic vertebral compression fractures: a prospective study. Spine (Phila Pa 1976). 2011;36(7):534-40.

3. Pluijm SM, Tromp AM, Smit JH, Deeg DJ, Lips P. Consequences of vertebral deformities in older men and women. J Bone Miner Res. 2000; 15(8):1564-72.

4. Longo UG, Loppini M, Denaro L, Maffulli N, Denaro V. Conservative management of patients with an osteoporotic vertebral fracture: a review of the literature. J Bone Joint Surg (Br). 2012;94(2):152-7.
5. Wardlaw D, Cummings SR, Van Meirhaeghe J, Bastian L, Tillman JB, Ranstam J, Eastell R, Shabe P, Talmadge K, Boonen S. Efficacy and safety of balloon kyphoplasty compared with non-surgical care for vertebral compression fracture (FREE): a randomised controlled trial. Lancet. 2009;373(9668):1016-24.

6. Garfin SR, Buckley RA, Ledlie J. Balloon kyphoplasty for symptomatic vertebral body compression fractures results in rapid, significant, and sustained improvements in back pain, function, and quality of life for elderly patients. Spine (Phila Pa 1976). 2006;31(19):2213-20.

7. Nieuwenhuijse MJ, van Erkel AR, Dijkstra PD. Percutaneous vertebroplasty in very severe osteoporotic vertebral compression fractures: feasible and beneficial. J Vasc Interv Radiol. 2011;22(7):1017-23.

8. Peh WC, Gilula LA, Peck DD. Percutaneous vertebroplasty for severe osteoporotic vertebral body compression fractures. Radiology. 2002;223(1):121-6.

9. McKiernan F, Faciszewski T, Jensen R (2003) Reporting height restoration in vertebral compression fractures. Spine (Phila Pa 1976) 28 (22):2517-2521; discussion 2513

10. Lyles KW, Gold DT, Shipp KM, Pieper CF, Martinez S, Mulhausen PL. Association of osteoporotic vertebral compression fractures with impaired functional status. Am J Med. 1993;94(6):595-601.

11. Esses SI, Sachs BL, Dreyzin V. Complications associated with the technique of pedicle screw fixation. A selected survey of ABS members. Spine (Phila Pa 1976). 1993;18(15):2231-8. discussion 2238-2239

12. Dickman CA, Fessler RG, MacMillan M, Haid RW. Transpedicular screw-rod fixation of the lumbar spine: operative technique and outcome in 104 cases. J Neurosurg. 1992;77(6):860-70.

13. Muijs SP, Nieuwenhuijse MJ, Van Erkel AR, Dijkstra PD. Percutaneous vertebroplasty for the treatment of osteoporotic vertebral compression fractures: evaluation after 36 months. J Bone Joint Surg (Br). 2009; 91(3):379-84.

14. Klazen CA, Lohle PN, de Vries J, Jansen FH, Tielbeek AV, Blonk MC, Venmans A, van Rooij WJ, Schoemaker MC, Juttmann JR, Lo TH, Verhaar HJ, van der Graaf $Y$, van Everdingen KJ, Muller AF, Elgersma OE, Halkema DR, Fransen $H_{\text {, }}$ Janssens X, Buskens E, Mali WP. Vertebroplasty versus conservative treatment in acute osteoporotic vertebral compression fractures (Vertos II): an open-label randomised trial. Lancet. 2010;376(9746):1085-92.

15. Denaro V, Longo UG, Maffulli N, Denaro L. Vertebroplasty and kyphoplasty. Clin Cases Miner Bone Metab. 2009;6(2):125-30.

16. Deramond H, Depriester C, Galibert P, Le Gars D. Percutaneous vertebroplasty with polymethylmethacrylate. Technique, indications, and results. Radiol Clin N Am. 1998;36(3):533-46.

17. Cotten A, Boutry N, Cortet B, Assaker R, Demondion X, Leblond D, Chastanet P, Duquesnoy B, Deramond H. Percutaneous vertebroplasty: state of the art. Radiographics. 1998;18(2):311-20. discussion 320-313

18. Hiwatashi A, Westesson PL. Vertebroplasty for osteoporotic fractures with spinal canal compromise. AJNR Am J Neuroradiol. 2007;28(4):690-2.

19. Shin JJ, Chin DK, Yoon YS. Percutaneous vertebroplasty for the treatment of osteoporotic burst fractures. Acta Neurochir. 2009:151(2):141-8.

20. Appel NB, Gilula LA. Percutaneous vertebroplasty in patients with spinal canal compromise. AJR Am J Roentgenol. 2004:182(4):947-51.

21. Li CH, Chang MC, Liu CL, Chen TS. Osteoporotic burst fracture with spinal canal compromise treated with percutaneous vertebroplasty. Clin Neurol Neurosurg. 2010;112(8):678-81.

22. Young C, Munk PL, Heran MK, Lane MD, Le HB, Lee S, Badii M, Clarkson PW, Ouellette HA. Treatment of severe vertebral body compression fractures with percutaneous vertebroplasty. Skelet Radiol. 2011;40(12):1531-6.

23. Garfin SR, Yuan HA, Reiley MA. New technologies in spine: kyphoplasty and vertebroplasty for the treatment of painful osteoporotic compression fractures. Spine (Phila Pa 1976). 2001:26(14):1511-5.

24. Nieuwenhuijse MJ, Van Erkel AR, Dijkstra PD. Cement leakage in percutaneous vertebroplasty for osteoporotic vertebral compression fractures: identification of risk factors. Spine J. 2011;1 (9):839-48.

25. Kim KH, Kuh SU, Chin DK, Jin BH, Kim KS, Yoon YS, Cho YE. Kyphoplasty versus vertebroplasty: restoration of vertebral body height and correction of kyphotic deformity with special attention to the shape of the fractured vertebrae. J Spinal Disord Tech. 2012;25(6):338-44.

26. Liu JT, Liao WJ, Tan WC, Lee JK, Liu CH, Chen YH, Lin TB. Balloon kyphoplasty versus vertebroplasty for treatment of osteoporotic vertebral compression fracture: a prospective, comparative, and randomized clinical study. Osteoporos Int. 2010;21(2):359-64. 